This is a post-peer-review, pre-copyedit version of an article published in Social Theory \& Health. The definitive publisher-authenticated version [Hannigan B. and Allen D. (2006) Complexity and change in the United Kingdom's system of mental health care. Social Theory \& Health 4 (3) 244-263] is available online at: http://www.palgrave-journals.com/sth/journal/v4/n3/abs/8700073a.html 


\title{
COMPLEXITY AND CHANGE IN THE UNITED KINGDOM'S SYSTEM OF MENTAL HEALTH CARE
}

\author{
ABSTRACT \\ In the context of wider efforts to improve efficiency and the user-centredness of health \\ and social care provision, public policy in the United Kingdom (UK) demonstrates an \\ explicit appeal to 'whole systems' management. This otherwise laudable attempt to \\ develop services may, however, reveal an underestimation by policymakers of how \\ complex systems of work can evolve in unpredictable ways. In this paper we utilise \\ sociological theories of the division of labour to underpin a wide-ranging case study of \\ the historical evolution and current characteristics of the ecology of mental health care in \\ the UK. Beginning with an analysis of the development of a system in which psychiatry \\ emerged as the lead profession, and progressing to a review of the challenges faced by \\ psychiatric knowledge and practice, we highlight the interrelated and dynamic features of \\ this system of work. Our paper closes with an examination of contemporary \\ 'modernisation', which we argue has the potential for triggering widespread system \\ disturbance.
}

\section{KEYWORDS}

division of labour; health care policy; mental health services; modernisation; occupations; organisational characteristics 


\section{INTRODUCTION}

Beginning with the insights of one of sociology's founding fathers (Durkheim, 1933), ecological theories of work have been developed and refined by successive generations of scholars (E Hughes, 1971; Abbott, 1988). In this paper we draw on ecological ideas which emphasise the world of work as a complex, dynamic and interrelated system to underpin a wide-ranging case study of the historical evolution and contemporary characteristics of mental health care in the United Kingdom (UK).

Trends in UK health and social care policymaking make our paper both timely and of interest to commentators and practitioners not otherwise concerned with the mental health field. Emerging policy reveals a shift towards 'whole systems' thinking (see for example: NHS Modernisation Agency, 2005). This development is driven by an explicit focus on improving both service efficiencies and how the needs of service users are met. Policy action is directed at managing the provision of integrated services through the development of system technologies aimed at engineering closer interoccupational and interagency working. Examples include the creation of shared standards, such as the use of national service frameworks, national guidelines and the development of integrated care pathways. Favourable conditions are also being created for the emergence of new occupational groups and for the configuration of new types of care team. For example, policy has explicitly contributed to the appearance of new mental health worker roles in primary care, and to the creation of new interprofessional teams focusing on the provision of services (such as assertive outreach) to closely-defined groups of users. The new policy context has also fostered conditions in which service providers are able to create 
new groups of workers, such as associate mental health practitioners, to meet locallyspecific needs.

This emergent approach to policy development and implementation is a significant attempt to improve services by more closely managing the unwieldy occupational and organisational division of labour associated with health and social care delivery. However, this version of whole systems thinking is both new and relatively underconceptualised. Policymakers may be underestimating the degree to which systems of work are liable to develop in unpredictable and unmanageable ways (Allen et al., 2004). Here we suggest that attempts to 'modernise' service delivery to better meet need, whilst laudable, run the risk of triggering significant unforeseen system disturbance. A principal aim of this paper, then, is to draw on theory and a broad historical perspective to highlight the complex ways in which systems of work evolve, and to raise awareness amongst policymakers, practitioners and others with a stake in the health and social care field of the potential for widespread and unpredictable change arising from developments currently taking place.

Whilst our view is that all systems of health and social care work are complex and in flux, for a number of specific reasons we suggest that the mental health field is a particularly appropriate one for our proposed analysis. First, mental health remains a highly contested area (Pilgrim and Rogers, 1999). The division of work in this system is also an unusually complicated one; this, too, makes our case study a particularly apposite 
one. Our critical analysis is also timely given the extent to which the provision of mental health services remains the focus of sustained worldwide attention.

\section{AN ECOLOGICAL PERSPECTIVE}

The Chicago sociologist Everett Hughes advanced the idea that the world of work is best thought of as a dynamic and interrelated social system (E Hughes, 1971). This ecological perspective is particularly revealed in his writings on occupations. For Hughes, an occupation refers to the part played by a group in the context of a larger system of work. He introduced the concepts of 'mandate' and 'licence' to draw attention to occupations' assertions about their status. An occupational mandate refers to the claims that a group makes about its particular contribution to society, whereas its licence refers to the actual terms of what members of that group are permitted to do distinct from the contribution of others. Hughes considered systems of work to be in flux, and evolving over time in response to wider processes (such as advances in specific technologies, and economic and social developments). Evolution of systems means that the 'bundle of tasks' (E Hughes, 1971, p313) attached to particular occupational groups may change, as can their social character. Challenges might also be mounted to an occupational group's licence and mandate, processes liable to lead to realignment of the boundaries between different occupational groups in an overall division of labour.

Abbott (1988) builds on the thinking of Hughes and his contemporaries associated with the Chicago School of Sociology. He also advances an ecological view of the world of work, but unlike Hughes is interested specifically in the system of professions. Building 
on Hughes' notions of licence and mandate, Abbott uses the term 'jurisdiction' to describe the control exercised by a professional group over an area of work. In dynamic systems jurisdictions are liable to change, in response to both internal and external forces. Like Hughes, Abbott implicates social, economic and technological changes as potential sources of system disturbance. System change can encompass the disappearance of some areas of work and the emergence of others, and a waxing and a waning in the fortunes of different groups. Abbott also emphasises the importance of interprofessional competition. Externally-driven changes in systems, for example, can present as opportunities for occupational groups to seize control of existing or emergent areas of work. For Abbott, what makes professions distinct in this context is their appeal to the possession of abstract knowledge, which is used to advance occupational status claims. Abstract knowledge, Abbott argues, is not an absolute but a relative concept; what matters to a profession's survival is 'abstraction effective enough to compete in a particular historical and social context' (Abbott, 1988, p9).

Abbott proposes that three arenas exist for the advancement of jurisdictional claims: the public, the legal and the workplace. Claims to professional jurisdiction in the public sphere tend to be limited. For example, Abbott notes that in public arenas claims are limited to those between apparently homogenous, archetypal groups. More enduring jurisdictional claims are made in the legal arena. There, control over specific areas of work may be cemented, sometimes lasting for decades or longer. However, preciselyworded legalistic settlements outlining the boundaries of professional work often bear little resemblance to the jurisdictions defended and advanced in real-life, interactive, 
workplaces. This real-life world of the workplace is Abbott's third arena for the advancement of professional claims. In situations where professionals work in organisations, the interprofessional division of labour is supplemented by an interorganisational division. Professionals in organisations are often required to assume new areas of work and give up others. Although job descriptions may attempt to delineate the boundaries between different groups, the actual work that professionals do is likely to bear little resemblance to what is enshrined on paper.

Taken together, Hughes' and Abbott's ecological ideas provide a powerful framework for investigations into the world of work. Their approach, which we draw on to underpin our case study of the system of mental health care, can be summarised thus:

[T] he societal division of labour is conceived of as a social system. Work is defined as the activities that need to be done in a given society and is not limited to paid work in the public sphere. The world of work is dynamic. System disturbance may arise from a number of sources: social, technological, economic and organizational change. Because the system of work is constantly in flux, occupations change. Jurisdictions expand and contract and the boundaries between paid and unpaid work domains may shift. New occupations emerge, others fuse and some may decline or disappear totally. The value and status of activities undertaken by an occupation may be modified. It is against this everchanging world that occupations vie to secure their standing.

(Allen, 2001, p41)

\section{THE EMERGENCE OF A SYSTEM OF MENTAL HEALTH WORK}

In the UK the formal system of mental health work began in the late eighteenth century with the large-scale construction of institutions dedicated to the segregation of madness (Rogers and Pilgrim, 2001), in which psychiatry emerged as the lead profession (Scull, 
1979). As Scull notes, psychiatry's dominance was linked to the profession's successful advancement of claims to possess knowledge of 'lunacy' as a disease with biophysical origins. Echoing the claims made by other branches of medicine at this time (Freidson, 1970), the jurisdiction asserted by 'mad doctors' during the nineteenth century came to be a wide-ranging one, encompassing the identification of mental disorder and determination of its cause, natural history and cure (Rogers and Pilgrim, 2001).

The social organisation of psychiatry and its autonomy and power were consolidated in the 1840s with the founding of both a professional association and a journal (Scull, 1979). Particularly long-lasting claims to control areas of work can be secured in the legal arena, and in the same decade psychiatry secured an advancement of its jurisdiction in this sphere with the passing of the 1845 Lunatics Act. This saw the establishment of a medically-dominated Lunacy Commission, which, Scull (1979) observes, exerted a powerful influence against the running of asylums by lay people. Psychiatry thus secured occupational closure (Witz, 1992) over the work of managing mental illness. A decade later, as Rogers and Pilgrim note, the jurisdiction of British psychiatry was sufficiently secure for an editorial in the Journal of Mental Science (now the British Journal of Psychiatry) to declare that: '[i]nsanity is purely a disease of the brain. The physician is now the responsible guardian of the lunatic and must ever remain so' (cited in Rogers and Pilgrim, 2001, p46).

Whilst doctors were successful in advancing their claims to control the emerging system of mental health care, most of the day-to-day work in the early asylums was carried out 
by attendants. Medical jurisdiction faced little challenge from this low-status group, however. No abstract body of knowledge existed to underpin their work, and many were employed solely on account of their practical skills or their physical strength (Nolan, 1993).

Ecological insights point to the dynamic character of systems of work, and highlight the ways in which system disruptions can arise from a variety of sources, both internal and external. Disturbance in the emergent system of mental health work from the end of the nineteenth century onwards was precipitated internally by advances in medical technologies. Underpinned by the psychiatric profession's claim to the possession of knowledge of madness as a disease with organic origins, greater use began to be made of physical treatments. These included the use of water, electricity, surgery and drugs (Prior, 1993). This greater employment of physical therapies required an expansion to the training of attendants to better enable them to undertake medically-delegated tasks (Dingwall et al., 1988). Formal education for this group, later designated as nurses, began at the end of the nineteenth century with the publication of The Handbook for the Instruction of Attendants on the Insane, along with the introduction of a Certificate in Nursing the Insane (Nolan, 1993).

\section{CHALLENGES TO THE JURISDICTION OF BIOMEDICAL PSYCHIATRY}

A distinctive feature of the mental health arena remains the contested underpinning abstract knowledge base claimed by the system's dominant group, biomedical psychiatry. One early threat to biophysical ideas and practices was moral treatment (Scull, 1979). As 
practised in institutions such as the York Retreat from the end of the eighteenth century, moral treatment was predicated on an understanding of insanity as arising from a disorder of the environment (Rogers and Pilgrim, 2001). Biomedical explanations of mental disorder have also been challenged by psychological abstractions, which grew in prominence from the early years of the twentieth century. More recently, from the 1960s onwards, significant social scientific and philosophical challenges to psychiatric orthodoxies and practice have been advanced, sometimes led by dissident members of the profession itself (Crossley, 1998).

Challenges to the jurisdiction claimed by the profession of biomedical psychiatry have also been mounted by newer occupational groups. For example, the expansion of medical technologies which followed psychiatry's success in the nineteenth century in advancing claims to the identification and treatment of mental disorder was highly consequential for the development of psychiatric nursing. Early nursing occupied a clearly subordinate position vis-à-vis medicine, with its bundle of tasks representing a delegation of routine activities by biomedical psychiatry centring on the provision of physical treatments. Systems evolve, however, and over time less powerful occupational groups will often seek to advance their positions. By the middle of the last century claims were being made for the possession of a distinct abstract knowledge base for psychiatric nursing, and a jurisdiction independent from medicine centred on the idea of the therapeutic nurse/patient relationship (Peplau, 1952). Whilst nurses in the UK tended to be more pragmatic and less theoretically-inclined than their North American counterparts (Tilley, 
1999), the possibilities of a distinctly 'nursing' contribution to the system of mental health work nonetheless took root.

\section{THE EMERGENCE OF COMMUNITY MENTAL HEALTH CARE}

Particularly significant in opening up opportunities for challenge to the jurisdiction of psychiatric knowledge and practice was the post-war emergence of a system of community care, an international phenomenon driven by a complex combination of powerful forces. Biomedical psychiatry's success in developing new physical treatments was noteworthy, particularly the synthesis of antipsychotic medications. More significant were macro-level social and cultural changes, which were reflected in ideological developments within mental health occupational groups. For example, post-war social psychiatry placed particular emphasis on environmental and interpersonal therapies in addition to physical treatments, whilst therapeutic communities questioned the idea of hierarchically organised hospital care (Goodwin, 1997).

The loosely-termed 'anti-psychiatry' movement was also important in challenging institutional care, as was the more general anti-institutions critique made by members of the civil rights and other social movements throughout the 1960s. Growing public tolerance of the presence of people with mental health problems, coupled with the expressed desire of members of the emerging mental health service user movement that care be provided in non-institutional settings, also helped drive community care forward (Goodwin, 1997). More radical interpretations of the mental health system of work's evolution towards non-institutional provision point to the primacy of economic 
considerations. Scull (1984), for example, argues that community care came into being for largely fiscal reasons, with deinstitutionalisation offering advantages to hard-pressed industrial capitalist societies intent on pursuing alternatives to costly hospital care.

A key place for the advancement of occupational jurisdictions is in real-life, interactive, workplaces. Large-scale system of work disturbances can originate in changes taking place in particularistic settings, where adjustments in local systems translate into opportunities for emergent groups to advance claims to control areas of work. The seismic shift in the system of mental health work which the emergence of community care represented began in this way, with small but highly consequential changes introduced under an 'open door' rubric - taking place in a handful of psychiatric hospital workplaces.

At Warlingham Park in Surrey, England, an open door policy was pursued through the unlocking of wards and a reduction in the time spent by patients inside the hospital (Nolan, 2003). Nurses also began to visit patients in their own homes, reporting back to the psychiatrist under whose supervision they worked. Whilst this extension of nursing practice into the community changed the sites in which nurses undertook their work it reportedly did little to alter local interoccupational relations or to challenge the authority of biomedical psychiatry. Early open door psychiatry was concerned less with a new vision of 'community care' than with 'treatment in the community' (Goodwin, 1989) and the extension of biomedical psychiatric jurisdiction. However, under the influence of social workers, at Moorhaven Hospital in Devon a more family-oriented approach to 
open door care was pursued. There, four nurses were recruited to provide services to patients and their families. Moorhaven was important for the occupational advancement of nursing, with an explicit aim being to make greater independent therapeutic use of nurses as the largest of the occupational groups concerned with the care of the mentally ill (Hunter, 1974). The Moorhaven nurses, then, were encouraged to purposefully intervene in the lives of their patients through the medium of the "therapeutic relationship' developed with both patients and their relatives.

\section{OCCUPATIONAL AND ORGANISATIONAL COMPLEXITY IN THE EMERGING SYSTEM OF COMMUNITY MENTAL HEALTH WORK}

Important differences exist between institutional systems of work and systems which are more distributed. In institutions, the work undertaken by different occupational groups is relatively visible. Subordinates are more obviously subject to the jurisdictional authority of dominant professions. The gradual emergence of a dispersed system of community care magnified considerably the potential for interoccupational complexity within the overall ecology of mental health care, and created new possibilities for jurisdictional challenge.

The extension of mental health care into people's homes created opportunities for occupational groups not obviously associated with the hospital-oriented system of mental health work. Social workers were a segmented (Bucher and Strauss, 1961) group, to be found working in a variety of practice areas. Training for social workers specialising in the mental health field had been available since the late 1920s, with early psychiatric 
social work practice being underpinned by the principles of psychoanalytic casework (McCrae et al., 2004). As a group social workers were supportive of community care initiatives (Goodwin, 1989), with some claiming an occupational mandate to deal with the practical social issues attendant to the provision of mental health care outside of hospitals (Hudson, 1982). Social workers had, for example, played an important part in influencing Moorhaven Hospital's family-oriented open door approach (Hunter, 1974).

In contrast to the biomedical assumptions which underpinned the jurisdictional authority of psychiatry, social work based its claims on an abstract knowledge base derived from the social sciences (Sheppard, 1991). Some social workers embraced a conceptual framework which acknowledged the biomedically-derived imperative of diagnosing and treating mental illness, whilst simultaneously attending to the practical family and other social issues associated with the provision of care in the community (Hudson, 1982). As Hudson notes, however, social work also included practitioners highly sceptical of biomedical psychiatry. Some, for example, advanced psychosocial models of 'mental illness' derived from anti-psychiatric and other radical critiques of psychiatric knowledge.

Abbott (1988) observes that in complex systems of work even the most powerful professions may need to cede full jurisdiction. Settlements between occupational groups can take a number of forms, from subordination of one group to another through to the construction of shared, interdependent, jurisdictions. The settlement between social work and the more powerful profession of psychiatry enabled social work practitioners to claim 
a limited jurisdiction dealing with the social practicalities associated with community care, and to participate in decision-making in the use of compulsory powers. The authority of social work was cemented in the legal sphere in both the 1959 and 1983 Mental Health Acts for England and Wales. The 1959 Act created the mental welfare officer role, whilst the 1983 Act created the new role of approved social worker with the responsibility for making applications for the compulsory admission of patients into hospital (McCrae et al., 2004). Both roles left unchallenged the psychiatric profession's jurisdictional authority to identify mental disorder, and to largely oversee the activities of other occupational groups in its treatment.

The system of community mental health work as this had emerged throughout the 1960s entered a period of externally-driven upheaval at the start of the following decade, triggered by changes in the legal sphere centring on the organisation of social work services. With the passing of the Local Authorities Act in 1970 local authority mental welfare officers and hospital-based psychiatric social workers were incorporated into generic social services departments (Sheppard, 1991). The subsequent loss of significant numbers of mental health social workers created a gap, or what Abbott (1988) calls a 'jurisdictional vacancy', in the system of care (Wooff et al., 1988). The relative demise of specialist mental health social workers at this time, complete with their social scientifically-derived body of abstract knowledge, provided psychiatrists with an opportunity to extend their influence over community care towards a more biomedical model. Thus the Royal Medico-Psychological Association (now the Royal College of Psychiatrists) was able to argue in a circular distributed to its members in 1969 that: '[i]t 
is likely that a new body of mental health social workers would have to be evolved to fill the gap left by the destruction of the present growing services, perhaps with an enhanced medical or nursing background' (cited in Hunter, 1974, p228).

This jurisdictional vacancy also presented itself as an opportunity for nurses to capture the social aspects of community mental health work. Unlike social work, the origins of mental health nursing lay in the asylum system, the power base for the profession of psychiatry (Nolan, 1993). Notwithstanding its efforts to generate an independent knowledge base and function, nursing still largely shared biomedical psychiatry's focus on the clinical manifestations of mental illness, as opposed to the more family and environmentally-oriented concerns of social work. For psychiatry, nursing was a subordinate group through which its authority could be advanced. In the community the bundle of tasks first attached to nursing was largely limited to the administration of longacting medications and other routinised activities associated with biomedical approaches to the treatment of mental illness in individuals (Godin, 1996). However, by the middle of the 1980s nursing was advancing claims to an expanded jurisdiction dealing with the family and environmental aspects of community care, underpinned by a new assertion to possess the requisite social scientific knowledge base (Simmons and Brooker, 1986).

The extension of mental health care into the community brought into sharp relief the interface between the system of mental health work and the system of family-oriented primary care. In the latter, general medical practitioners (GPs) were the dominant professional group. For many GPs the new availability of dedicated mental health 
services in the community presented itself as an opportunity to share the care of people with common mental health problems such as depression and anxiety. Community mental health nurses, in particular, were welcomed as useful new members of an extended primary care team able to take on work which GPs claimed an underpinning abstract knowledge for but were unable to do due to time constraints (Hannigan, 1997). For nursing, providing therapies in primary care served as a useful professionalising strategy which enabled its practitioners to negotiate a more equal settlement with GPs, as a counter to the subordinate position which they occupied with psychiatrists (Godin, 1996).

\section{A FOCUS ON LOCALITIES: INTERPROFESSIONAL AND INTERAGENCY COMMUNITY MENTAL HEALTH TEAMS}

Policymakers in the UK have long been occupied with the search for means of improving the coordination of health and social care services, and specific policy initiatives directed to this end have precipitated widespread system of work disruptions. For example, the idea of bringing together different occupational groups into single teams with the aim of providing more coordinated care in the community for people with mental health problems was first suggested in Better Services for the Mentally Ill (Department of Health and Social Security, 1975). Thereafter the community mental health team (CMHT) became the key mental health services organisational innovation of the late 1970s onwards.

The appearance of CMHTs was highly significant for the system of mental health work. Teams were potentially a site for workplace interoccupational jurisdictional competition, 
but also offered the prospect of occupational differences being dissolved in the pursuit of shared goals. Initially termed community mental health centres (CMHCs) in the style of their United States predecessors, CMHT numbers doubled every two years throughout the late 1980s (Sayce et al., 1991). By the early 1990s over 500 were in existence in England (Onyett et al., 1994). Continued political commitment to the CMHT model was demonstrated in the Building Bridges document (Department of Health, 1995), which reaffirmed the multiprofessional team as the most appropriate means of delivering care.

Within single workplaces CMHTs typically brought together psychiatrists, nurses, generically-prepared social workers electing to specialise in the mental health field, occupational therapists, clinical psychologists, unqualified support workers and administrative staff (Onyett et al., 1994), with nurses and social workers the most frequently-encountered groups. The authority of social workers to formally participate in decision-making over the use of compulsory powers had been enshrined in the legal sphere since the end of the 1950s. The authority of nurses to carry out medicallydelegated tasks such as the administration and monitoring of medications was also wellestablished. Beyond these areas significant space existed for interoccupational competition, including over the provision of individual and family-oriented therapies and attention to the practical social tasks attendant to providing care in the community (Sheppard, 1991).

However, it was representatives of the less numerous groups, notably occupational therapists and clinical psychologists, who were amongst the most vocal in expressing 
doubts over the CMHT model. For example, loss of professional identity (J Hughes, 2001) and the erosion of a 'unique' contribution (Parker, 2001) were feared by occupational therapists. Within clinical psychology - a group which had laid strong claims to the possession of an abstract knowledge base relating to both 'normal' and 'abnormal' psychological functioning - working in interprofessional CMHTs was seen by some as an unattractive career aspiration (Gasiorek, 1998). Psychologists were also reported to be the occupational group most in favour of a return to single-profession teams (Mistral and Velleman, 1997).

Systems of work in which divisions between occupations are supplemented by divisions between organisations or agencies are likely to be particularly unstable, with organisational imperatives exerting a powerful (and sometimes constraining) influence over professional jurisdictions. With most CMHTs funded by both health and social care bodies, changes at the agency level often had significant implications for groups and their bundles of tasks. For example, externally-driven modifications to the responsibilities of local authorities introduced in the legal sphere through the NHS and Community Care Act of 1990 triggered changes in the role of social workers. Care management obliged social services departments to assume more of an 'enabling' function, which for social workers translated into a reduction in opportunities for therapeutic practice and an increase in administrative responsibilities (McCrae et al., 2004).

A further source of system disturbance has come from the increasingly confident actions of the mental health service user and lay carer movements. Social movements of these 
types have exerted a powerful influence in many health and social care systems (Brown and Zavestoski, 2005). In recent years the system of mental health care, hitherto dominated by health and social care occupational groups and their employing agencies, has been required to adjust in response to bottom up pressure for greater involvement from service users and carers (see for example: Peck and Barker, 1997). These forces have been augmented by the new managerialist theme of 'consumerism' and the expectation that '...users of services should be involved as far as possible in the care process' (Department of Health, 1995, p38). For many mental health practitioners, the idea of forging closer and more equal working relationships with users has been an appealing one. In addition to the rewards to be derived from working in this way (Onyett et al., 1995), for occupational groups such as nursing which have been attempting to develop jurisdictions independent from medicine, aligning with users of services has potentially been one way of resisting medical dominance.

\section{MENTAL HEALTH CARE AT THE TURN OF THE CENTURY}

In recent years all parts of the UK's public services have been subjected to increasingly intense scrutiny by the state, with the aim of improving efficiency, effectiveness and the service user experience (6 and Peck, 2004a). Mental health care has emerged as a priority area for reform (6 and Peck, 2004b), with contemporary 'modernisation' representing an attempt from the centre to more tightly manage a particularly complex system of work.

This development is significant for a number of reasons. At a theoretical level, extensive and direct state intervention with the aim of improving the day-to-day functioning of 
systems is an eventuality not particularly envisaged by either Hughes (1971) or Abbott (1988), for whom ecologies of work are largely self-regulating. However, intervention from the state is now a major source of disturbance in the UK's system of mental health work. As this paper's historical analysis shows, change in one part of an interrelated and dynamic ecology - from whatever source - can reverberate elsewhere. In this final section of our paper, in examining the contours of modernisation we draw attention to the impact this is having on the mental health system, and point to those areas where policymakers might be advised to pursue a less interventionist stance.

Throughout the early years of the last decade UK mental health care was widely perceived to be in crisis. Occupational and agency jurisdictions were unclear and often contested, a problem compounded by the under-funding of services (Audit Commission, 1994). Serious questions were also being asked in the public sphere about the capacity of the mental health system to deliver safe and effective care to vulnerable, and sometimes dangerous, groups of service users. Service failures were widely reported in the national media, with lack of role clarity within different parts of the system typically being cited as key to understanding these (see for example: Ritchie et al., 1994). Initial policy responses saw a new emphasis on the management of risk (see for example: National Health Service Management Executive, 1994), and an early proposal to redraw the organisational relationships between health care and social care bodies (Department of Health, 1997). 
Central intervention has expanded considerably since the election of New Labour to government in 1997, under the leadership of Tony Blair. Like other parts of the public services modernisation programme, reform of mental health care is being driven by a policymaking version of a whole systems approach. England's Mental Health Policy Implementation Guide, for example, includes discussion of the need for system-wide change involving all agencies, occupational groups and other parties with a stake in mental health care provision (Department of Health, 2001a). Since 1997 specific interventions in the mental health system have expanded to include: the introduction of evidence-based national service frameworks (NSFs) (see for example: Department of Health, 1999; Welsh Assembly Government, 2005) and national guidelines (see for example: National Institute for Clinical Excellence, 2002); an increase in the division of community mental health labour through the setting up of new 'functional specialist' teams (see for example: Department of Health, 2001a); and explicit attention to the composition of the mental health workforce (see for example: Department of Health, 2001b) and the roles and responsibilities of different occupational groups (see for example: Department of Health, 2004a; Department of Health, 2005).

\section{MODERNISATION AND THE ECOLOGY OF MENTAL HEALTH WORK}

Modernisation is triggering widespread and unpredictable change in the ecology of mental health care. National service frameworks and national guidelines, for example, represent an attempt to more closely prescribe arrangements for the delivery of services in the workplace, and to encourage greater uniformity in provision (Allen and Pilnick, 2005). Both appeal to the use of evidence to inform the development of services, but do 
so in a top-down way. Standardisation of this type has potentially far-reaching implications for occupations and their ability to exercise control over their work. Backed by a process of inspection, centrally-determined standards - where these change actual working practices, as opposed to just changing the ways in which workers write about their activities in official records - have the potential to alter the relationship between occupational groups and the state in favour of the latter.

A further way in which modernisation carries the potential for standardising the content of professional work is through the use of integrated care pathways (ICPs). ICPs are an emerging health technology, designed to streamline service provision, promote evidencebased interprofessional and interagency working and, in some instances, precipitate changes in the division of labour. ICPs relate to specific disorders, and outline the problems, effective interventions and expected outcomes associated with health and social care delivery (Jones, 2004). In the mental health context ICPs remain relatively under-developed, and where introduced (for example, to assist the local implementation of national guidelines) have met with mixed responses (Jones, 2004; Rayner, 2005). One area of concern, for example, is that care pathways - like other standardising guidelines may constrain the provision of user-focused services.

Guidelines and care pathways are associated with the idea that greater attention should be paid to the use of evidence to inform decision-making, a trend with strong roots in professional practice. However, modernisation is associated with a particularly managed, top-down, approach to the development of evidence-based health and social care. The 
appeal of shared standards lies in their claim to promote uniformly high quality services. This potential attraction to occupational groups may be tempered, however, if policydriven standardisation significantly constrains their ability to determine the content of their work. Restricting professional autonomy in the workplace, under the rubric of improving effectiveness and efficiency, may be one of modernisation's implicit aims. However, whilst requiring occupational groups to practise in particular ways may be attractive to policymakers intent on reducing unacceptable variations in quality of care, the drive towards greater standardisation may simultaneously erode the creative appeal of work in health and social care settings. This may have significant, and unintended, negative consequences for staff morale, recruitment and retention.

Standardisation may also inadvertently reinforce hierarchies within and between occupational groups. Significant power rests with those in a position to construct guidelines and care pathways. New professional elites may emerge, their influence derived from claims to possess a requisite knowledge base to underpin their creation of standards which others are expected to follow. Adding to these complexities are the possible reactions of service users and their organised representatives. Modernisation's commitment to the provision of individually-tailored and user-focused care sits uneasily with the simultaneous drive towards the delivery of more uniform services. Service users have significantly grown in confidence and become more organised in the mental health system, and the success - or otherwise - of the drive towards managed standard-setting may hinge in part on their response to this trend. 
The mental health modernisation agenda also entails a policy shift towards multidisciplinary teams in the community with an emphasis on specific functions (Peck, 1999). Unlike sectorised CMHTs, services of this type (such as assertive outreach, and crisis intervention and home treatment teams) eschew comprehensiveness in favour of the selective care and treatment of closely-defined groups of people. Functional specialist teams offer practitioners from diverse occupational backgrounds new opportunities to unite around clear sets of goals, in ways which were often lacking in locality CMHTs (Peck, 2003). As with the creation of national standards, these developments are directed towards more effectively meeting service users' needs. However, as Peck notes, the growth in team types also makes for a more fragmented division of labour, and increases the potential for inter-team barriers to effective whole system working.

The appearance of new types of team may also lead to a greater segmentation within occupational groups, and add to the likelihood of increased competition over control of areas of work. Intra-occupational divisions can reflect differences in the characteristics of those on the receiving end of a group's collective services (Abbott, 1988). Working with certain types of service recipients - like those needing more 'assertive' mental health services - can appear particularly attractive to practitioners. Intra-group hierarchies of prestige may emerge, with certain types of work appealing at the expense of others. Particularly in the context of a static or diminishing workforce, the gravitation of practitioners towards higher status work risks creating significant gaps in overall systems of care. 
The emergence of a more complex division of labour at the team and organisational levels is also creating conditions favourable for the emergence of new occupational groups. In England, a long-standing jurisdictional vacancy in the provision of primary care based mental health services is being partially filled by a new type of mental health practitioner drawn from the ranks of psychology graduates (Department of Health, 2000). In addition, adjustments to localised systems of mental health work are happening in response to particular, situation-specific, needs. For example, as a solution to the problem of a depleted workforce in Hampshire, England, graduates holding health or social carerelated degrees can train as Associate Mental Health Practitioners (AMHPs) (http://www.nursingandmidwifery.soton.ac.uk/AMHP/intro.htm). Although early evaluations of the England-wide graduate workers initiative suggest that these new entrants to the ecology of mental health work are struggling to find a distinct jurisdictional space (Bower et al., 2004), predicting the longer-term consequences of system disruptions of this type is difficult. A historical perspective, however, points to the ways in which localised or small-scale changes carry the potential for significant systemwide disruptions, with implications for occupations and their work.

Actual and proposed changes in the legal sphere are also formally redefining the associations between established occupational groups and their bundles of tasks. The extension of nurse prescribing to include those working in the mental health field points towards an end to the medical profession's sole and exclusive licence in this area (Department of Health, 2002). Also, part of New Labour's solution to the problem of managing risk has been to produce draft legislation for England and Wales which, if 
enacted, promises to strip social workers of their exclusive responsibility to apply for the use of compulsory powers in favour of a jurisdiction shared with others (Department of Health, 2004b). These are significant developments which promise to alter occupational boundaries. Changing the associations between groups and their tasks in this way can trigger change in the social character of those groups, and can presage highly consequential fluctuations in occupational fortunes.

The introduction of new occupational groups into the workforce, and the loosening of the associations between groups and their tasks, bring the potential for protracted inter-group competition and radical realignments in the division of mental health labour. Occupational groups may form alliances to stake joint jurisdictional claims, or, faced with marginalisation in an increasingly fragmented system, fuse together. Others, faced with the loss of their bundle of tasks, may even disappear from the system of mental health work altogether. Early evidence of uncertainty over roles and responsibilities is demonstrated by recent government-sponsored reviews of the work of two of the main mental health occupational groups, psychiatry (Department of Health, 2004a) and nursing (Department of Health, 2005). Fuelling this complexity will be the claims of the service user movement. Invigorated by appeals to the possession of the experiential knowledge of successful strategies for recovery from mental illness, users may stake their own jurisdictional claims to control work in opposition to the claims advanced by paid practitioners. 


\section{CONCLUSION}

This case study analysis of the origins, development and contemporary features of the UK's system of mental health care illustrates the complex and dynamic character of ecologies of work. The historical exemplars discussed demonstrate the degree to which, in an interrelated system, change in one part can reverberate elsewhere with significant consequences for the system as a whole. Sources of system disturbance are varied, and examples highlighted here include advances in technologies, interoccupational competition, social and ideological developments, and policy interventions.

The health and social care policy agenda currently in train has potentially far-reaching implications for the ecology of mental health work. Devolution of policymaking to elected assemblies throughout the different countries of the UK adds a further layer of complexity. Whilst shared themes can be discerned throughout the UK as a whole, significant national differences in emphasis also exist, the detail of which lies beyond the scope of this paper. Here we conclude by arguing that evidence from history, and theoretical insights, point towards the possibility of profound system disturbance flowing from the modernisation project. Given this, a reflective pause by policymakers may now be appropriate in order to better permit an examination of the intended and unintended system reverberations triggered by changes already introduced.

\section{ACKNOWLEDGEMENTS}

The study from which this paper is drawn was partially supported through the award of a 2000 Smith and Nephew Foundation Nursing Research Fellowship. The authors would 
like to extend their thanks to the Foundation, and also to Michael Coffey, Michelle Huws-Thomas, Steve Wood and Norman Young for their helpful comments on earlier drafts of this manuscript.

\section{ABOUT THE AUTHORS}

Ben Hannigan is a Senior Lecturer in Mental Health Nursing in the School of Nursing and Midwifery Studies, Cardiff University, UK. He has published widely in the fields of mental health policy and practice.

Davina Allen is a Professor and Director of the Nursing, Health and Social Care Research Centre and the Wales Centre for Evidence Based Practice, School of Nursing and Midwifery Studies, Cardiff University, UK. She has published widely on the organisation of health and social care and on the accomplishment of nursing roles.

\section{REFERENCES}

6 P, Peck E (2004a). 'Modernisation': the ten commitments of New Labour's approach to public management? International Public Management Journal 7: 1-18.

6 P, Peck E. (2004b). New Labour's modernization in the public sector: a neoDurkheimian approach and the case of mental health services. Public Administration 82: 83-108. 
Abbott A (1988). The system of professions: an essay on the division of expert labor. University of Chicago Press: Chicago.

Allen D (2001). The changing shape of nursing practice: the role of nurses in the hospital division of labour. Routledge: London.

Allen D, Griffiths L, Lyne P (2004). Understanding complex trajectories in health and social care provision. Sociology of Health and Illness 26: 1008-1030.

Allen D, Pilnick A (2005). Making connections: healthcare as a case study in the social organisation of work. Sociology of Health and Illness 27: 683-700.

Audit Commission (1994). Finding a place: a review of mental health services for adults. London: HMSO.

Bower P, Jerrim S, Gask L (2004). Primary care mental health workers: role expectations, conflict and ambiguity. Health and Social Care in the Community 12: 336345.

Brown P, Zavestoski S (2005). Social movements in health: an introduction. Sociology of Health and Illness 26: 679-694.

Bucher R, Strauss A (1961). Professions in process. American Journal of Sociology 66: 325-334. 
Crossley N (1998). RD Laing and the British anti-psychiatry movement: a sociohistorical analysis. Social Science and Medicine 47: 877-889.

Department of Health (1995). Building bridges: a guide to arrangements for interagency working for the care and protection of severely mentally ill people. Department of Health: London.

Department of Health (1997). Developing partnerships in mental health. The Stationery Office: London.

Department of Health (1999). A national service framework for mental health. Department of Health: London.

Department of Health (2000). The NHS Plan: a plan for investment, a plan for reform. Department of Health: London.

Department of Health (2001a). The mental health policy implementation guide. Department of Health: London.

Department of Health (2001b). Mental health national service framework (and the NHS Plan) workforce planning, education and training underpinning programme: adult mental health services. Final report by the Workforce Action Team. Department of Health: London. 
Department of Health (2002). Prescribing within the NHS in England: a guide for implementation. Department of Health: London.

Department of Health (2004a). Guidance on new ways of working for psychiatrists in a multi-disciplinary and multi-agency context. Department of Health: London.

Department of Health (2004b). Draft Mental Health Bill. Department of Health: London.

Department of Health (2005). Chief Nursing Officer's review of mental health nursing: consultation document. Department of Health: London.

Department of Health and Social Security (1975). Better services for the mentally ill. HMSO: London.

Dingwall R, Rafferty A-M, Webster C (1988). An introduction to the social history of nursing. Routledge: London.

Durkheim E (1933). The division of labour in society. Collier-Macmillan: London.

Freidson E (1970). Profession of medicine: a study of the sociology of applied knowledge. Harper and Row: New York.

Gasiorek B (1998). Safety in numbers. Clinical Psychology Forum 120: 29-31. 
Godin P (1996). The development of community psychiatric nursing: a professional project? Journal of Advanced Nursing 23: 925-934.

Goodwin S (1989). Community care for the mentally ill in England and Wales: myths, assumptions and reality. Journal of Social Policy 18: 27-52.

Goodwin S (1997). Comparative mental health policy: from institutional to community care. Sage: London.

Hannigan B (1997). A challenge for community psychiatric nursing: is there a future in primary health care? Journal of Advanced Nursing 26: 251-257.

Hudson B L (1982). Social work with psychiatric patients. Macmillan: Basingstoke.

Hughes E (1971). The sociological eye: selected papers on work, self and the study of society. Aldine: Chicago.

Hughes J (2001). Occupational therapy in community mental health teams: a continuing dilemma? Role theory offers an explanation. British Journal of Occupational Therapy 64: $34-40$.

Hunter P (1974). Community psychiatric nursing in Britain: an historical review. International Journal of Nursing Studies 11: 223-233. 
Jones A (2004). Perceptions on the standardization of psychiatric work: development of a care pathway. Journal of Psychiatric and Mental Health Nursing 11: 705-713.

McCrae N, Murray J, Huxley P, Evans S (2004). Prospects for mental health social work: a qualitative study of attitudes of service managers and academic staff. Journal of Mental Health 13: 305-317.

Mistral W, Velleman R (1997). CMHTs: the professionals' choice? Journal of Mental Health 6: 125-140.

National Health Service Management Executive (1994). Introduction of supervision registers for mentally ill people from 1 April 1994. Department of Health: Leeds.

National Institute for Clinical Excellence (2002). Schizophrenia: core interventions in the treatment and management of schizophrenia in primary and secondary care. National Institute for Clinical Excellence: London.

NHS Modernisation Agency (2005). Improvement leaders' guide: working in systems. Department of Health: London.

Nolan P (1993). A history of mental health nursing. Chapman and Hall: London. 
Nolan P (2003). The history of community mental health nursing. In Hannigan B, Coffey M (eds.). The handbook of community mental health nursing. Routledge: London. pp 718

Onyett S, Heppleston T, Bushnell D (1994). The organisation and operation of community mental health teams in England: a national survey. The Sainsbury Centre for Mental Health: London.

Onyett S, Pillinger T, Muijen M. (1995). Making community mental health teams work: CMHTs and the people who work in them. The Sainsbury Centre for Mental Health: London.

Parker H (2001). The role of occupational therapists in community mental health teams: generic or specialist? British Journal of Occupational Therapy 64: 609-611.

Peck E (1999). Introduction to special section on community mental health teams. Journal of Mental Health 8: 215-216.

Peck E (2003). Working in multidisciplinary community teams. In Hannigan B, Coffey M (eds.). The handbook of community mental health nursing. Routledge: London. pp 6777

Peck E, Barker I (1997). Users as partners in mental health: ten years of experience. Journal of Interprofessional Care 11: 269-277. 
Peplau H (1952). Interpersonal relations in nursing. G.P. Putnam and Sons: New York.

Pilgrim D, Rogers A (1999). A sociology of mental health and illness, $2^{\text {nd }}$ edn. Open University Press: Buckingham.

Prior L (1993). The social organization of mental illness. Sage: London.

Rayner L (2005). Language, therapeutic relationships and individualised care: addressing these issues in mental health care pathways. Journal of Psychiatric and Mental Health Nursing 12: 481-487.

Ritchie JH, Dick D, Lingham R (1994). The report of the inquiry into the care and treatment of Christopher Clunis. HMSO: London.

Rogers A, Pilgrim D (2001). Mental health policy in Britain, $2^{\text {nd }}$ edn. Palgrave: Basingstoke.

Sayce L, Craig TKJ, Boardman AP (1991). The development of community mental health centres in the UK. Social Psychiatry and Psychiatric Epidemiology 26: 14-20.

Scull AT (1979). Museums of madness: the social organization of insanity in nineteenthcentury England. Allen Lane: London.

Scull A (1984). Decarceration. Community treatment and the deviant: a radical view, $2^{\text {nd }}$ edn. Polity Press: Cambridge. 
Sheppard M (1991). Mental health work in the community: theory and practice in social work and community psychiatric nursing. Falmer: London.

Simmons S, Brooker C (1986). Community psychiatric nursing: a social perspective. Butterworth-Heinemann: Oxford.

Tilley S (1999). Altschul's legacy in mediating British and American psychiatric nursing discourses: common sense and the 'absence' of the accountable practitioner. Journal of Psychiatric and Mental Health Nursing 6: 283-295.

Welsh Assembly Government (2005). Raising the standard: the revised adult mental health national service framework and an action plan for Wales. Welsh Assembly Government: Cardiff.

Witz A (1992). Professions and patriarchy. Routledge: London.

Wooff K, Goldberg DP, Fryers T (1988). The practice of community psychiatric nursing and mental health social work in Salford: some implications for community care. British Journal of Psychiatry, 152, 783-792. 